\title{
HABITAT STRUCTURE AND COLONIAL BEHAVIOR IN METEPEIRA SPINIPES (ARANEAE: ARANEIDAE), AN ORB WEAVING SPIDER FROM MEXICO
}

\author{
By George W. UetZ ${ }^{1}$ and J. Wesley Burgess ${ }^{2}$
}

\section{INTRODUCTION}

The topic of social phenomena in spiders has received much attention in the literature recently (Shear 1970; Kullman 1972; Burgess 1976, 1978; Buskirk, in press). Colonial, communal and cooperative behaviors have been observed in a variety of families and genera, mostly from tropical and subtropical regions around the world. Among the species of group-living spiders found in Mexico and Central America is Metepeira spinipes F. Pickard-Cambridge, an araneid reported to be the only colonial species in its genus (Levi 1977). We observed large numbers of these spiders in Central Mexico in 1975, and were able to collect some data, which we present here.

\section{Methods AND Study ARea}

The site of our observations was Tepotzotlan, Mexico, located 35 $\mathrm{km}$ North of Mexico City. The area is an agricultural valley surrounded by mountains (thus the habitat must be considered "disturbed" by the activities of humans). Major agricultural activities include cultivation of corn and maguey (an Agave sp. grown to make pulque, a fermented beverage) with open range grazing of cattle, and several feedlots. Our visit took place in late July 1975, during the rainy season. Temperatures were typically warm during the day $\left(20-30^{\circ} \mathrm{C}\right)$ and cool at night $\left(5-15^{\circ} \mathrm{C}\right)$. It generally rained once a day in the late afternoon $15-17 \mathrm{~h}$ pm CST).

Metepeira spinipes spiders were studied in 3 sites, all located near the KOA campground where we stayed. One site, a roadside, contained a variety of types of vegetation, including Agave, Opuntia,

\footnotetext{
'Department of Biological Sciences, University of Cincinnati, Cincinnati, Ohio 45221.

${ }^{2}$ North Carolina Mental Health Research, Raleigh, North Carolina 27611 [Present address: Department of Psychology, University of California, Davis, California 95616].

Manuscript received by the editor June 28, 1979
} 
Acacia (?) trees and numerous unidentified shrubs, forbs and grasses. This roadside area was bordered on one side by a large cornfield and on the other by an irrigation ditch. A second roadside area was perpendicular to the first, bordering the same cornfield. This site has a larger irrigation ditch, the sides covered by dense, low growing willows (Salix sp.). A third site, a maguey plantation, was located approximately $1.2 \mathrm{~km}$ east of the other sites. The area was planted in large $(>1.5 \mathrm{~m})$ Agave (approximately 5-7 yrs old), interspersed with grasses and occasional trees. The plantation has the appearance of an Agave "orchard", due to the semi-regular dispersion of the large plants. These three areas represent the characteristic habitats where Metepeira were found in the Tepotzotlan area.

To assess habitat preferences of Metepeira, a series of $6200 \mathrm{~m}^{2}$ quadrats was delineated in the roadside area containing a variety of vegetation types. Within each quadrat, the percent cover and percent volume of each vegetation type was estimated. Frequency of occurrence of Metepeira spinipes, (both colonies and solitary individuals) was recorded within each vegetation type.

In both the maguey plantation and the roadside ditch covered by willows, counts were made of spider group size. In addition, measurements of colonial web dimensions and habitat dimensions were made for selected groups.

\section{RESULTS AND DISCUSSION}

The web of individual Metepeira spinipes is characteristic of the genus, and is a three-dimensional space web/orb web composite with a retreat in the space web (also called a barrier web; Levi 1977) (Fig. 1). Signal threads connect the hub of the spiral and the retreat, where the spider rests (Burgess \& Witt 1976). Only the threads of the orb's spiral are sticky, and the orb is the primary prey catching device. Prey are often entangled in the space web and occasionally are caught there. Individuals of $M$. spinipes in Central Mexico usually occur in aggregations, although solitary individuals of this species are also found. Most of the groups we examined consisted of 5-30 individuals, but much larger groups (50-80) were seen. In the groups we observed, individuals had their own retreats and orbs but space webs were joined. Although orbs are usually renewed on a daily basis (spiders rebuild radii and sticky spirals during the night) 


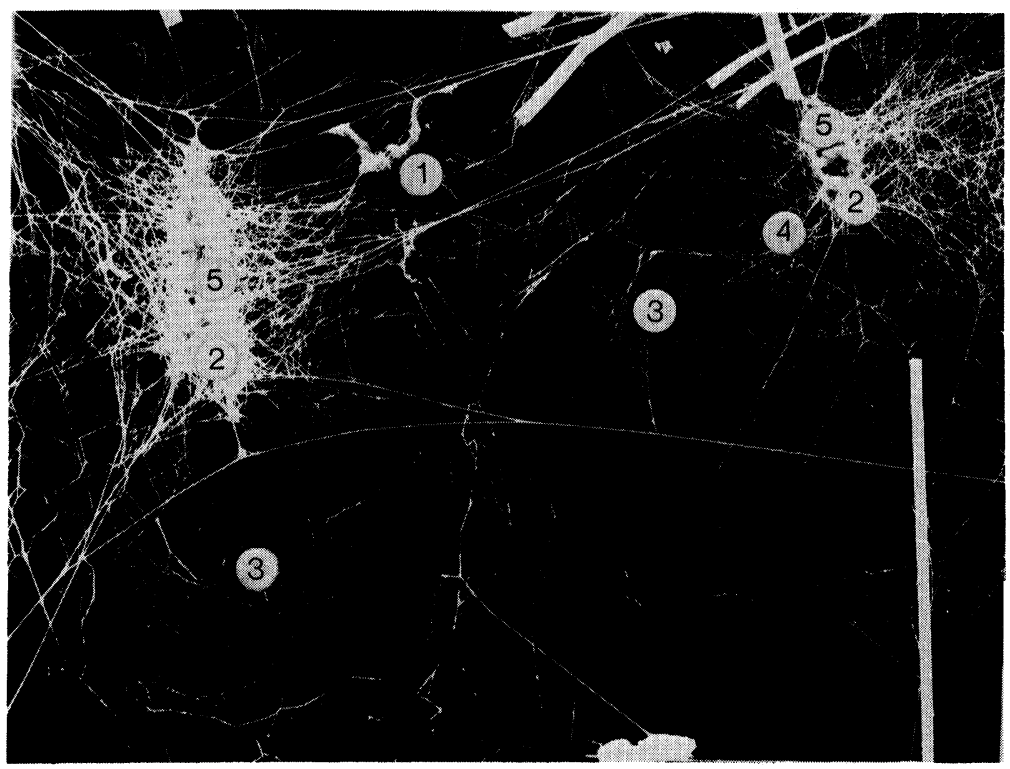

Figure 1. Metepeira spinipes, compound web. (1) Space web; (2) retreat where spider sits, holding signal threads (4) to (3) catching spiral. Mature females may construct tiers of egg sacs (5). [Courtesy of Dr. Peter N. Witt, North Carolina Division of Mental Health and Mental Retardation Services. Used with permission.]

the colonial space web persists and is elaborated on by the web building activities of numerous individuals. The resultant colonial web is a mass of interconnected individual webs supporting each other, attached at its periphery to the vegetation. The colonies we observed contained adults and immatures of indeterminate age and wide size variation.

Metepeira spinipes colonial webs are usually associated with microhabitats of a somewhat permanent structure: succulents, dead branches, shrubs, man-made objects, etc. In the Tepotzotlan area, maguey (Agave sp.) plants were the most common site of $M$. spinipes colonies. Habitat preferences of this species were examined in an area containing a variety of microhabitat types. The null hypotheses that spiders are equally distributed in all microhabitat types, or are distributed on the basis of the frequency of occurrence of microhabitat types are rejected based on Chi-square tests (Table 1). These data suggest that $M$. spinipes colonies and/or individuals occur more frequently in Agave plants than in other microhabitat sites. 
Most of the solitary individuals were found in grasses and forbs, but in frequencies proportionate to the occurrence of that type of microhabitat.

There are several possible reasons why $M$. spinipes exhibit a habitat preference for the maguey plant. Agave sp. are perennial, succulent plants with stiff leaves capable of providing strong support for web attachments. These plants have lanceolate leaves with cupped leaf bases, radiating from a basal rosette. Such a leaf arrangement provides much support for the three-dimensional colonial web. Colinvaux (1973) suggests that plants with physiognomy similar to Agave sp. (i.e. Yucca) are adapted for arid environments, in that their leaf shape reduces heat load, and cupped leaf bases concentrate moisture. Agaves might be a localized source of moisture during the dry season, or even at mid-day during the rainy season when solar radiation is intense and humidity is low. We have observed water accumulating at the base of some plants. There is also some evidence that agaves are sites of high insect activity. Debris from nearby flowering plants and trees and other organic matter sometimes accumulates about the base of these plants. Decomposition of this matter and lower leaves of older agaves attracts flying insects, creating a microhabitat with extremely abundant prey resources.

These findings raise questions about the nature of $M$. spinipes aggregations. Do these spiders exhibit grouping tendencies that may be considered social, or do they exist in fortuitous aggregations associated with habitat resources that are patchily distributed? There is some evidence that these spiders aggregate independently of habitat. The mean colony size of $M$. spinipes in two contrasted microhabitat sites, Agave sp. and shrubs is not significantly different (Table 1). Although other Metepeira species are associated web sites of a particular architecture (McCook 1889; Kaston 1948; Levi 1977), M. spinipes is not. This species occurs in a variety of web sites with widely varying structure. Moreover, the shape of the web colony is flexible, and conforms to that of the web site. This suggests, at least, that coloniality of $M$. spinipes is independent of habitat structure. Spiders brought into the laboratory and released into cages build colonial webs, attaching silk of one animal to silk of another. Moreover, individuals from different colonies, even as far apart as several hundred miles, tolerate each other and build webs together (Burgess 1976). This evidence strongly suggests that $M$. 
Table 1. Distribution of Metepeira spinipes in several microhabitat types.

\begin{tabular}{lccccc}
\hline Microhabitat & Agave & Opuntia & Trees & Shrubs & $\begin{array}{c}\text { Grasses } \\
+ \text { Forbs }\end{array}$ \\
\hline percent cover & 4.3 & 1.0 & 4.6 & 5.0 & 85.1 \\
percent volume & 4.9 & 2.3 & 20.9 & 7.6 & 64.4 \\
$\begin{array}{l}\text { No. of spiders } \\
\text { No. of colonies }\end{array}$ & 691 & 16 & 2 & 96 & 17 \\
$\begin{array}{l}\bar{\chi} \text { colony ( } \pm 2 \text { S.E.) } \\
\text { size }\end{array}$ & 47 & 1 & 0 & 9 & 3 \\
$\begin{array}{l}\text { No. of solitary } \\
\text { individuals }\end{array}$ & $14.67 \pm 3.38$ & 16.0 & - & $14.89 \pm 8.1$ & $2.0 \pm 0.0$ \\
\hline
\end{tabular}

Tests of significance:

no. of spiders no. of colonies

no. of solitary individuals

$\mathrm{H}_{\mathrm{o}}=$ equal frequencies in all microhabitat types

$\begin{array}{lrr}\chi^{2}=2141.8 & \chi^{2}=93.7 & \chi^{2}=22.12 \\ \mathrm{p}<.001 & \mathrm{p}<.001 & \mathrm{p}<.01\end{array}$

$\mathbf{H}_{0}=$ frequencies proportionate to percent cover of micro-habitat type

$\begin{array}{lrr}\chi^{2}=12922.1 & \chi^{2}=646.7 & \chi^{2}=6.9 \\ \mathrm{p}<.001 & \mathrm{p}<.001 & .2<\mathrm{p}<.3\end{array}$

$\mathrm{H}_{\mathrm{o}}=$ frequencies proportionate to percent volume of micro-habitat type

$\chi^{2}=11188.0$

$\mathrm{p}<.001$

$\chi^{2}=551.5$

$\chi^{2}=3.11$

$.5<\mathrm{p}<.6$

spinipes aggregations arise from some kind of interattraction, not from habitat patchiness.

Another means of gathering evidence for or against a social tendency to aggregate is an analysis of the frequency distribution of group size. In a study of web-clumping in Nephila clavipes, Farr (1977) compared group size distributions to a Poisson distribution truncated at zero. His data fit the distribution, and he concluded that web clumping by $N$. clavipes is a random process. Using methods described in A. Cohen (1960) and J. Cohen (1971), we attempted this with data on $M$. spinipes group size from two contrasted habitats (the maguey plantation and the willow shrub ditch described in methods). In both habitats, the distribution of spider 
group size was significantly different from a zero-truncated Poisson distribution (Tables 2 and 3), indicating a non-random grouping pattern. The distribution did fit a zero-truncated Negative Binomial distribution (Tables 2 and 3), indicating a significant tendency to aggregate. The fact that group size in $M$. spinipes occurs with the same underlying aggregated distribution in such divergent habitat types argues for the existence of a social grouping tendency rather than fortuitous aggregation. While it may be argued that in Agaves, structural habitat resources are concentrated in small patches, this was not the case in the willow shrubs. The willow shrubs appeared to be uniformly dense and of equal height and age. There was no a priori reason to suspect that web site resources for $M$. spinipes

Table 2. Frequency distribution of group size in Metepeira spinipes colonies in Agave plants.

\begin{tabular}{|c|c|c|c|c|c|}
\hline \multirow{2}{*}{$\frac{\text { Group Size }}{1}$} & \multirow{2}{*}{$\begin{array}{c}\text { Observed } \\
\text { Frequency }\end{array}$} & \multicolumn{2}{|c|}{$\begin{array}{c}\text { Truncated } \\
\text { Poisson }\end{array}$} & \multicolumn{2}{|c|}{$\begin{array}{l}\text { Truncated } \\
\text { Negative } \\
\text { Binomi }\end{array}$} \\
\hline & & .0001 & \multirow{9}{*}{1.71} & $.651\}$ & \multirow{2}{*}{1.46} \\
\hline 2 & 0 & .0009 & & $.811\}$ & \\
\hline 3 & 1 & .005 & & .914 l & \multirow{2}{*}{1.89} \\
\hline 4 & 2 & .017 & & $.977\}$ & \\
\hline 5 & 0 & .050 & & $1.010^{\circ}$ & \multirow{5}{*}{1.95} \\
\hline 6 & 2 & .124 & & 1.010 & \\
\hline 7 & 0 & .259 & & 1.010 & \\
\hline 8 & 2 & .475 & & .988 ( & \\
\hline 9 & 0 & .775 & & $.958\}$ & \\
\hline 10 & 0 & 1.136 & & .9201 & \multirow{2}{*}{1.80} \\
\hline 11 & 0 & 1.515 & & $.881\}$ & \\
\hline 12 & 1 & 1.850 & & $.840\}$ & \multirow{2}{*}{1.63} \\
\hline 13 & 2 & 2.090 & & $.790\}$ & \\
\hline 14 & 1 & 2.190 & & $.745\}$ & \multirow{2}{*}{1.44} \\
\hline 15 & 1 & 2.140 & & $.699\}$ & \\
\hline 16 & 0 & 1.960 & & $.654\}$ & \multirow{2}{*}{1.26} \\
\hline 17 & 1 & 1.690 & & $.610\}$ & \\
\hline 18 & 0 & 1.38 & & $.570\}$ & \multirow{2}{*}{1.10} \\
\hline 19 & 1 & 1.06 & & $.530\}$ & \\
\hline 20 & 0 & .78( & \multirow{2}{*}{2.28} & .49 । & \\
\hline \multirow[t]{3}{*}{$>20$} & 7 & $1.50\}$ & & $5.95\}$ & 6.44 \\
\hline & 21 & & & & \\
\hline & & \multicolumn{2}{|c|}{$\begin{array}{c}\chi^{2}=34.06 \\
p<.005\end{array}$} & \multicolumn{2}{|c|}{$\begin{array}{l}\chi^{2}=11.98 \\
.5<\mathrm{p}<.6\end{array}$} \\
\hline
\end{tabular}


spiders were aggregated in any way in the willow shrub area, thus a social aggregation hypothesis is supported.

The colonial web of Metepeira spinipes is a permanent aggregation of individual prey catching orb webs in a matrix of communal space web. Burgess (1978) has suggested that cooperative behavior of "Social" spiders consists of simultaneous coordination of individual effort on a task, like web-building. In $M$. spinipes the colonial web would appear to arise as the result of simultaneous or sequential (but not coordinated) individual efforts at web building, rather than cooperative behavior. Prey catching orbs are spaced apart and each spider inhabits its own retreat. Although individuals may coexist at short distances, intruders on the spiral are met with agonistic behavior (Web shaking, chasing, etc.). In many solitary and aggregated spider species, maintenance of a personal space or territory by aggressive behavior has been shown (Buskirk 1975 and in press, Riechert 1978, Burgess 1978). The combination of solitary and colonial behaviors exhibited by this species suggests that it represents an intermediate stage in the evolution of social behavior in spiders.

In a colonial web like that of $M$. spinipes, where space webs are three-dimensional and highly interconnected, it is not possible to discern clearly the space web made by one individual vs. another. We measured the dimensions of polygonal colonial webs and counted individuals and orbs in the field, and from these we have estimated how the volume of the colonial web is subdivided by individuals (Fig. 2). The amount of space per individual in a colonial web decreases dramatically as colony size increases from 2-10 individuals. However, in larger colonies, there appears to be a lower limit on the amount of space per individual. The asymptote in figure 2 possibly reflects the minimal individual space requirements of $M$. spinipes. These values are probably underestimates of the actual amount of individual space, since there are often more individuals in a colony than there are orbs. The compressibility of individual space in aggregations of varying size shown by this species indicates a degree of tolerance of conspecifics beyond that expected if individuals' webs were merely attached to one another.

Riechert (1978 and personal communication) has found that territory size in a desert sheet web spider (Agelenopsis aperta (Gertsch)) decreases with increased habitat quality over a wide range of areas. The size of the area occupied by an individual Agelenopsis spider is 
Table 3. Frequency distribution of group size in Metepeira spinipes colonies in low willows (Salix sp.).

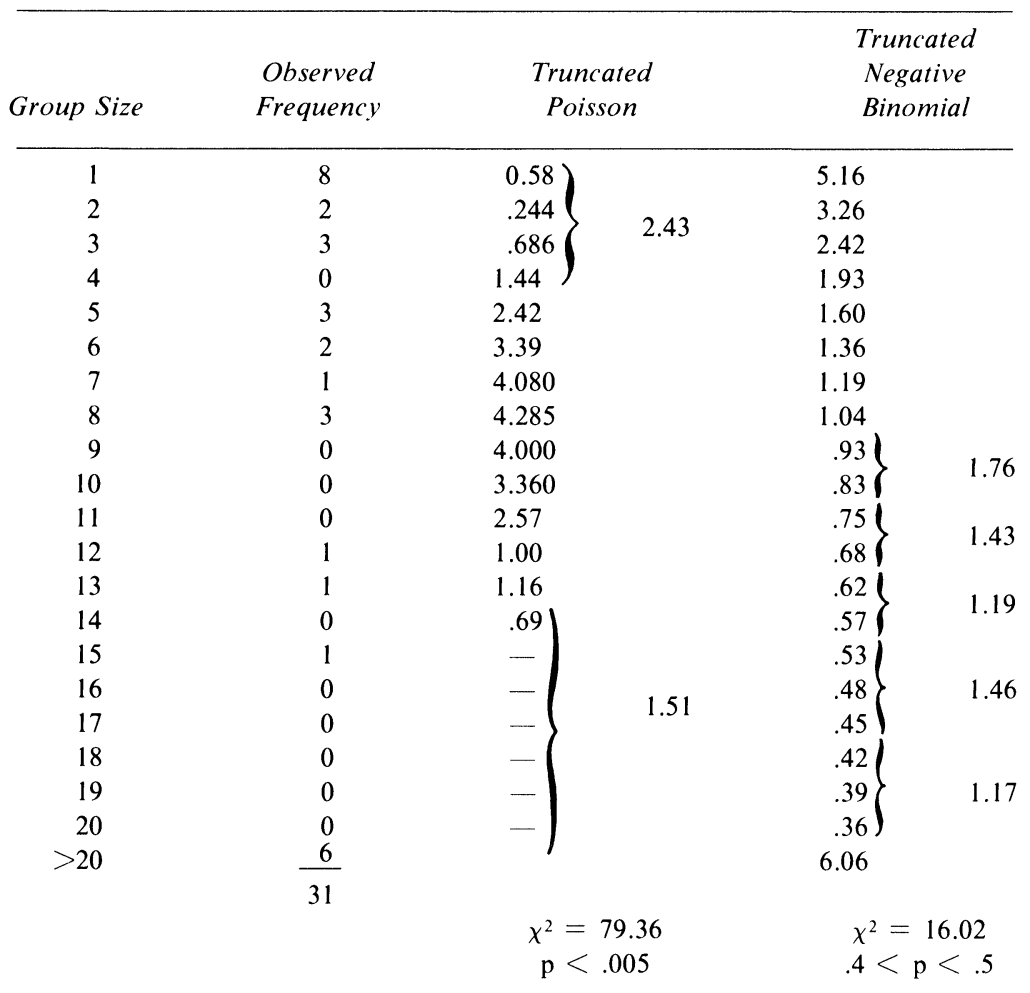

related to its energy needs and to the accessibility of prey (based on prey abundance and microclimatic stress limits on prey catching time) in a habitat. An energy-based territorial system might be part of a hypothesis generated to explain the evolution of social phenomena in spiders like $M$. spinipes. In habitats where accessibility to prey is high, territory size and inter-individual distance would be reduced, and populations would be large. If available web sites (providing architectual support for a 3 dimensional web as in solitary Metepeira) were limited, selection would favor individuals capable of living in an aggregated state. Behaviors favoring group occupation of web sites (increased tolerance of conspecifics, interattraction) would be selected for, although behaviors associated with 
maintenance of individual space (web defense etc.) would be retained.

There are many other selective advantages to group living that might also apply to the evolution of coloniality in M. spinipes. By locating space webs together, spiders gain additional "knock-down" structures which may serve to increase prey taken. The colonial space web creates a stronger foundation on which to build individual orbs, and may allow energy savings in web maintenance costs. The colonial web also transmits vibrations, and may be an important means of communication of predator attack or prey availability. Prey stealing and web take-over are often seen in $M$. spinipes and other species, and suggest that spiders may benefit from living in an aggregation without building a web. The mate selection process is facilitated by group living, and males may increase their fitness by "attending" a female (we have observed this) before she molts to adulthood. Colonies of spiders like $M$. spinipes can monopolize larger, or better quality web sites, while solitary species

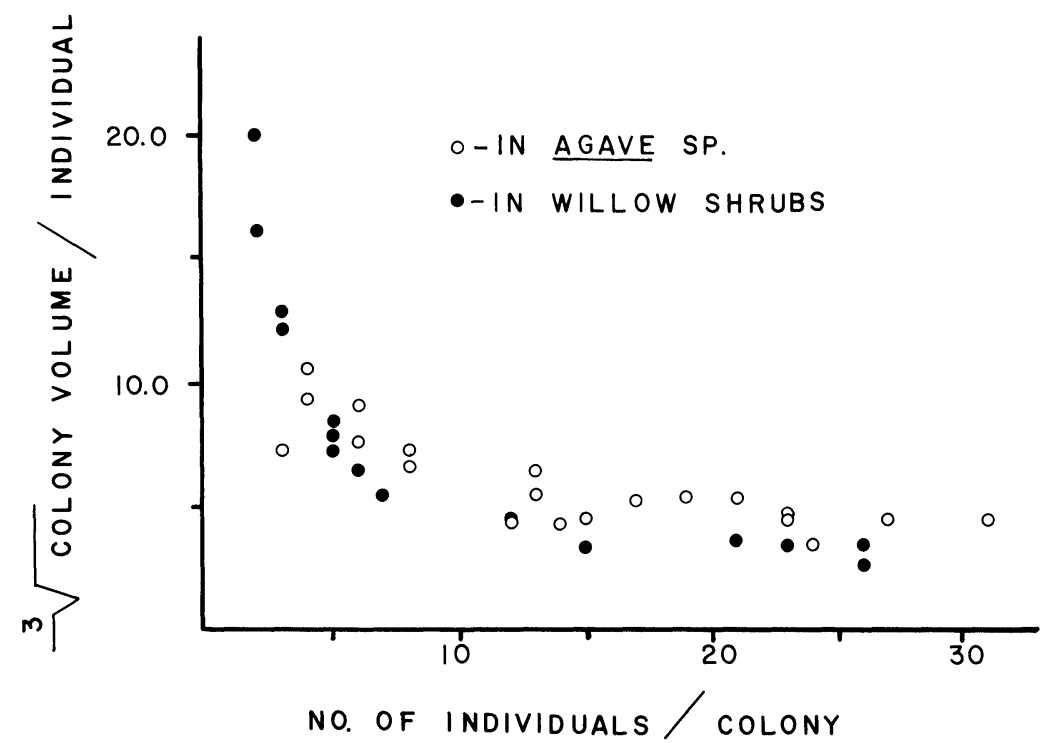

Figure 2. Amount of colony volume per individual $M$. spinipes over a range of colony sizes. (Colony volume in $\mathrm{cm}^{3}$ is expressed as a cube root for linear comparison with number of individuals.) 
may not. (For more detailed discussion see Shear 1970; Kullman 1972; Lubin 1974; Burgess 1978; Buskirk, in press).

Hopefully, future research on this species and other group living spiders will shed more light on the evolution of sociality in an otherwise asocial group of animals.

\section{SUMMARY}

Data on habitat preference and group size in Metepeira spinipes F. P.-Cambridge, a colonial orb weaving spider from Central Mexico, are presented. $M$. spinipes colonies are associated with microhabitats of permanent structure, and occur most frequently in maguey plants (Agave sp.). Colony size appears to be independent of microhabitat structure. Distribution of group size in two contrasted habitats (Agaves and willows) showed a significant difference from a zero-truncated Poisson distribution and a good fit to a zero-truncated Negative Binomial distribution, indicating a tendency to aggregate independently of habitat. Amount of individual space decreased with increased colony size, indicating a tolerance of conspecifics greater than expected if spiders merely attached individual webs together. The combination of solitary and colonial behaviors exhibited by this species suggests that it may represent an intermediate stage in the evolution of social behavior in orbweaving spiders. Possible selective advantages to group-living in this species and the evolution of coloniality are discussed.

\section{ACKNOWLEDGEMENTS}

This research was supported in part by National Science Foundation grant BNS-75-09915-A03 to Dr. Peter Witt. Additional financial assistance by Ms. Colette Croze is gratefully acknowledged. Thanks to Peter Witt and Thomas Kane for reviewing the manuscript. Special thanks to Joan Sattler, who typed the manuscript.

\section{REFERENCES Cited}

BURGESS, J. W.

1976. Social spiders. Sci. Amer. 234: 100-106.

1978. Social behavior in group-living spider species. Symp. Zool. Soc. Lond. 42: $69-78$.

Burgess, J. W. \& P. N. WitT.

1976. Spider webs: design and engineering. Interdisc. Sci. Review. 1: 322-335. 
BUSKIRK, R. E.

1975. Aggressive display and orb defense in a colonial spider, Metabus gravidus. Anim. Behav. 23: 560-567.

in Sociality in the Arachnida. In. H. R. Hermann, ed., Social Insects, Vol. II, press. Chap. 7, Academic Press.

COHEN, A. C., JR.

1960. Estimating the parameter in a conditional Poisson distribution. Biometrics 16: 203-211.

COHEN, J. E.

1971. Casual groups of monkeys and men. Harvard Univ. Press, Cambridge, Mass. 175 p.

Colinvaux, P. A.

1973. Introduction to Ecology. J. Wiley \& Sons, N.Y. 621 p.

FARR, J. A.

1977. Social behavior of the Golden Silk Spider, Nephila clavipes. J. Arachnol. 4: $137-144$.

KASTON, B. J.

1948. Spiders of Connecticut. Conn. Geol. \& Nat. Hist. Surv. 70. pp. 226-227. KULLimanN, E. J.

1972. Evolution of social behavior in spiders (Araneae: Eresidae and Theridiidae). Amer. Zool. 12: 419-426.

LEVI, H. W.

1977. The orb weaver genera Metepeira, Kaira and Aculepeira in America North of Mexico (Araneae: Araneidae). Bull. Mus. Comp. Zool. 148: $185-238$.

LuBIN, Y. D.

1974. Adaptive advantages and the evolution of colony formation in Cyrtophora (Araneae: Araneidae). Zool. J. Linn. Soc. 54: 321-339.

МсСоок, H. C.

1889. American spiders and their spinning work. Vol. I. publ. by the author. Acad. Nat. Sci. Phila. 369 p.

RIECHERT, S. E.

1978. Energy-based territoriality in populations of the desert spider, Agelenopsis aperta (Gertsch). Symp. Zool. Soc. Lond. 42: 211-222.

Shear, W. A.

1970. The evolution of social phenomena in spiders. Bull. Brit. Arachnol. Soc. 1: 65-76. 

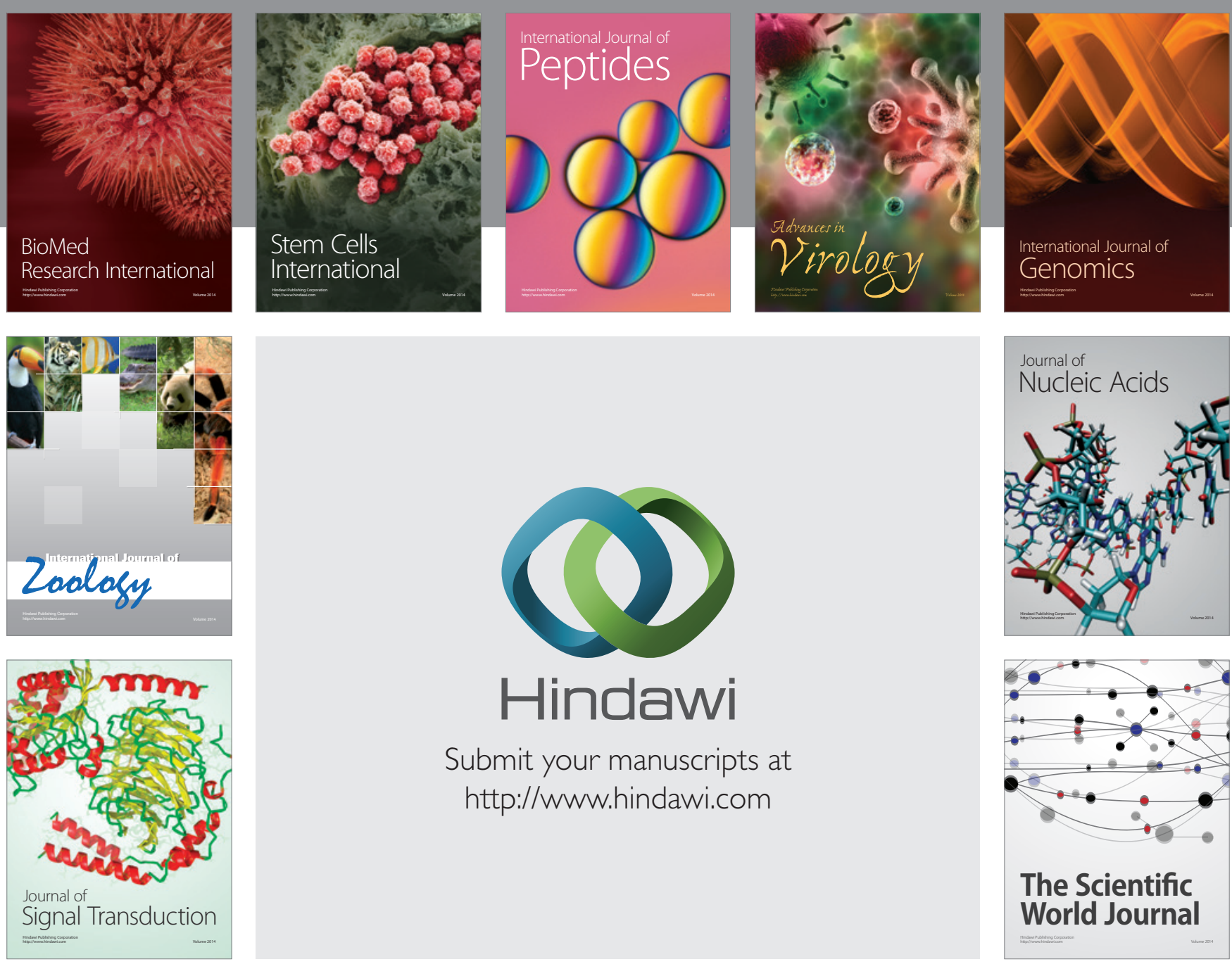

Submit your manuscripts at

http://www.hindawi.com
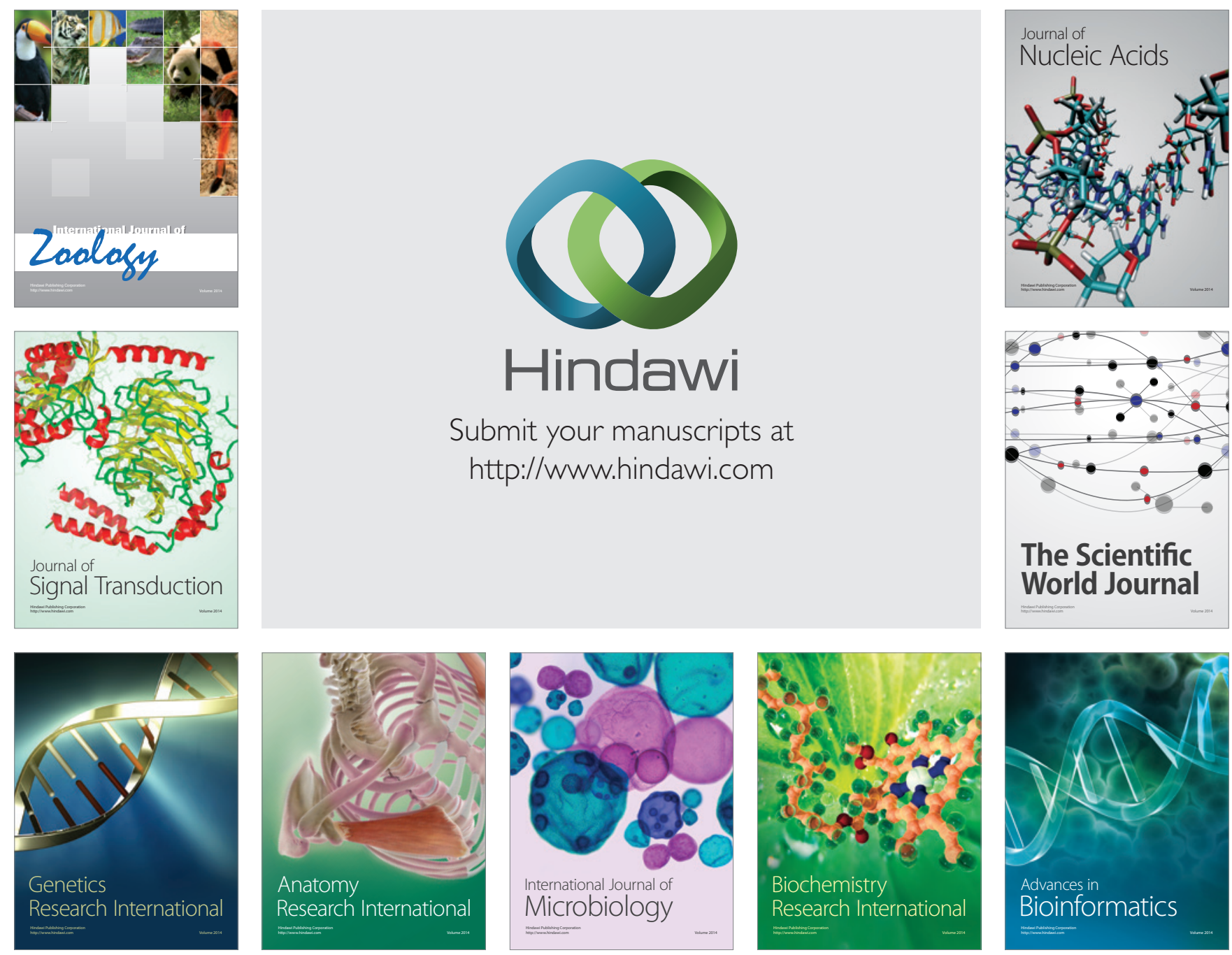

The Scientific World Journal
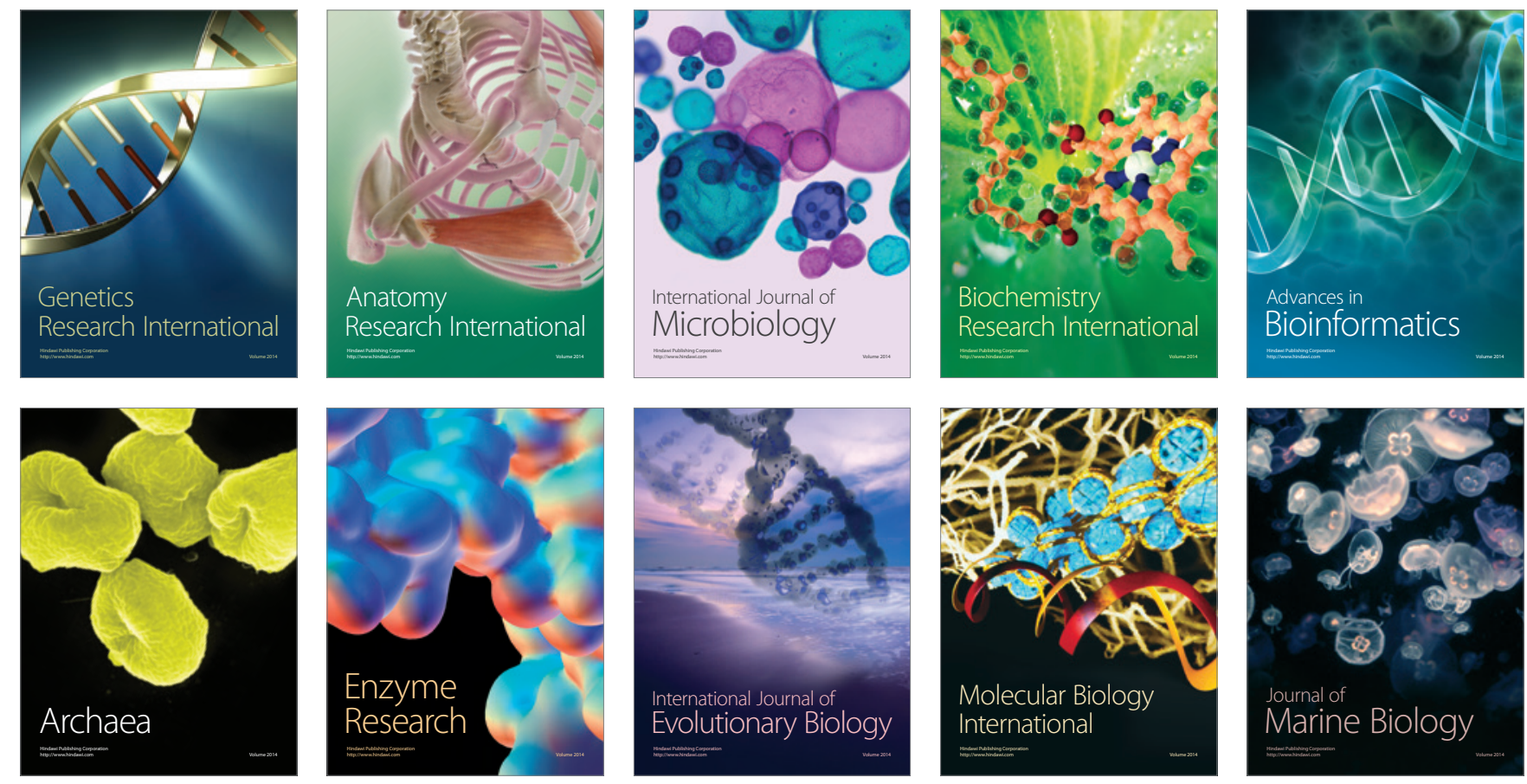